BMJ Nutrition,

Prevention \& Health

\section{Time for nutrition in medical education}

To cite: Macaninch $\mathrm{E}$, Buckner L, Amin P, et al. Time for nutrition in medical education. BMJ Nutrition, Prevention \& Health 2020;3:e000049. doi:10.1136/ bmjnph-2019-000049

- Additional material is published online only. To view please visit the journal online (http://dx.doi.org/10.1136/ bmjnph-2019-000049).

For numbered affiliations see end of article.

\section{Correspondence to}

Dr Kathy Martyn, SHS, University of Brighton, Brighton BN21 1 NP, UK;

k.j.martyn@brighton.ac.uk and

Professor Sumantra Ray, St John's Innovation Centre, NNEdPro, Cambridge, CB4 OWS, UK; s.ray@nnedpro.org.uk

$E M$ and $L B$ are joint first authors $\mathrm{KM}$ and SR are joint senior authors.

Received 20 August 2019 Revised 18 February 2020 Accepted 19 February 2020 Published Online First 16 April 2020

\section{ABSTRACT}

Aim To synthesise a selection of UK medical students' and doctors' views surrounding nutrition in medical education and practice.

Methods Information was gathered from surveys of medical students and doctors identified between 2015 and 2018 and an evaluation of nutrition teaching in a single UK medical school. Comparative analysis of the findings was undertaken to answer three questions: the perceived importance of nutrition in medical education and practice, adequacy of nutrition training, and confidence in current nutrition knowledge and skills.

Results We pooled five heterogeneous sources of information, representing 853 participants. Most agreed on the importance of nutrition in health $(>90 \%)$ and in a doctor's role in nutritional care (>95\%). However, there was less desire for more nutrition education in doctors $(85 \%)$ and in medical students $(68 \%)$. Most felt their nutrition training was inadequate, with $>70 \%$ reporting less than 2 hours. There was a preference for face-to-face rather than online training. At one medical school, nutrition was included in only one module, but this increased to eight modules following an increased nutrition focus. When medical students were asked about confidence in their nutrition knowledge and on advising patients, there was an even split between agree and disagree $(p=0.869$ and $p=0.167$, respectively), yet few were confident in the UK dietary guidelines. Only $26 \%$ of doctors were confident in their nutrition knowledge and $74 \%$ gave nutritional advice less than once a month, citing lack of knowledge $(75 \%)$, time $(64 \%)$ and confidence $(62 \%)$ as the main barriers. There was some recognition of the importance of a collaborative approach, yet $28 \%$ of doctors preferred to get specialist advice rather than address nutrition themselves. Conclusion There is a desire and a need for more nutrition within medical education, as well as a need for greater clarity of a doctor's role in nutritional care and when to refer for specialist advice. Despite potential selection bias and limitations in the sampling frame, this synthesis provides a multifaceted snapshot via a large number of insights from different levels of training through medical students to doctors from which further research can be developed.

\section{INTRODUCTION}

Nutrition-related risk factors are linked to both acute and chronic disease, contributing significantly to a large burden of preventable non-communicable diseases and increasing the risk of premature death. ${ }^{1}$ Within healthcare, we are facing the triple burden of
What this paper adds

- A first synthesis of the views of medical students and junior doctors in the UK about Nutrition education

- An understanding of what nutrition related teaching medical students feel is needed in their undergraduate curriculum

- Insights into the need to clarify the role of the doctor in nutritional care

malnutrition, comprising three overlapping themes of overnutrition, undernutrition and micronutrient deficiencies. ${ }^{2}$

In January 2019, the National Health Service (NHS) in the UK published a 'Longterm-plan' which calls for a greater focus on prevention of disease and public health. ${ }^{2}$ As such there is commitment to improving obesity and diabetes prevention services, alongside reducing health inequalities. Clause 2.19 explicitly states 'frontline staff need to feel equipped to talk about nutrition and maintaining weight in an informed and sensitive way', yet some medical schools have at most 8 hours of nutrition training. ${ }^{3}$

Around $10 \%$ of adults visiting their general practitioners and a third of patients on admission to hospital or care homes are undernourished or at risk of undernourishment, ${ }^{4}$ but this remains poorly recognised and addressed within primary or secondary care settings. ${ }^{5}$

Further to this, the latest UK National Diet and Nutrition Survey reveals deficiencies across all age groups in iron, vitamin $\mathrm{D}$ and folate, increasing population risks of anaemia, osteoporosis and neural tube defects in pregnancy. ${ }^{6}$

The economic consequence of undernutrition was estimated to cost the UK $£ 19.6$ billion in 2011-2012. This equates to $15 \%$ of the total expenditure on health and social care, meaning a reduction of just $1 \%$ corresponds to a saving of $£ 196$ million. ${ }^{7}$ Conversely, NHS England spent $£ 6.1$ billion for obesity-related ill health from 2014 to $2015 .^{8}$

There is general consensus that medical practitioners should engage in providing 
nutritional advice ${ }^{9}$ and have a greater understanding of the role food plays both in health and disease. Research from Australia identifies that such advice from doctors is held in high regard by the general public. ${ }^{10}{ }^{11}$ However, there is widespread concern that medical education does not adequately prepare doctors for this role. ${ }^{12}$ It is agreed that without robust nutrition education in medical undergraduate programmes we are unlikely to see any improvements in nutritional care within medical practice. ${ }^{1314}$

This paper is a narrative synthesis of results from heterogeneous instruments which have collected small but insightful perspectives on nutrition in medical education. This forms part of the Need for Nutrition Education Programme's (NNEdPro) Nutrition Education Policy in Healthcare Practice (NEPHELP) project, which aims to first landscape the areas of need within medical nutrition training, then develop a training programme to address these needs before evaluating its impact.

\section{Aims}

This paper contributes to the landscaping of need within medical nutrition training through summarising the observations of survey data and a UK medical school curriculum review that analyse the beliefs of medical students and junior doctors on the standard of nutrition teaching in medical education. This synthesis allows discussion around both the amount of time and emphasis given to nutrition in medical education, and importantly where the major gaps currently exist.

\section{METHODS}

Medical student and doctor opinions of nutrition training were gathered by accumulating data from a curriculum review of nutrition content, teaching evaluations and available heterogeneous surveys of medical students and doctors identified between 2015 and 2018, as summarised in figures 1 and 2.

Methods for the curriculum review and surveys are summarised based on the methods reported by the student and junior doctors who designed the surveys and completed the data collection. Data were analysed by EM, $\mathrm{LB}$ and $\mathrm{KM}$, who were not involved with the design or data collection of the original surveys. Where possible we have estimated sample sizes using publicly available numbers of medical students. However, while acknowledging the flaws in individual data collection, heterogeneous designs and small sample sizes, overall data were pooled where there were recurrent themes. From this, a comparative analysis of the findings was undertaken using the following three questions:

1. Do medical students or doctors believe nutrition in medical education and clinical practice is important? What further training do they feel they need?

2. How much nutrition content is there in current training and what are the preferred learning methods?

3. How confident are doctors in their nutrition knowledge and skills? What is the self-perceived role of doctors in nutritional care?

The ERimNN-led (Education and Research in Medical Nutrition Network) curriculum review and subsequent curriculum development of the nutrition curriculum in a single medical school between 2015 and 2018 followed an action research methodology, which encompassed a cycle of evaluation, implementation, review and reflection $^{15}$ (figure 2). Nutrition content was mapped against lecture titles, learning objectives and assessment tasks. These were compared with the UK General Medical Council's (GMC) expected learning outcomes identified

\begin{tabular}{|c|c|}
\hline Survey & Purpose \\
\hline An ERImNN curriculum review & $\begin{array}{l}\text { Assess the amount of Nutrition education in the medical curricula of a } \\
\text { medical school }\end{array}$ \\
\hline $\begin{array}{l}\text { The ERImNN led student } \\
\text { evaluations }\end{array}$ & $\begin{array}{l}\text { To evaluate the perceived effects of student selected component as well } \\
\text { as nutrition education in the curricula }\end{array}$ \\
\hline $\begin{array}{l}\text { A Nutritank (student medical } \\
\text { society) online survey }\end{array}$ & $\begin{array}{l}\text { To assess the opinions of medical students regarding their current } \\
\text { nutrition training }\end{array}$ \\
\hline $\begin{array}{l}\text { A doctor led online survey of } \\
\text { medical students }\end{array}$ & $\begin{array}{l}\text { To assess the opinions of medical students regarding their nutrition } \\
\text { training as well as looking at differences between clinical and pre-clinical } \\
\text { students }\end{array}$ \\
\hline $\begin{array}{l}\text { The NNEdPro led semi- } \\
\text { qualitative online survey } \\
\text { medical students }\end{array}$ & To assess where medical students want further training within nutrition \\
\hline $\begin{array}{l}\text { A Nutritank online junior } \\
\text { doctor survey }\end{array}$ & $\begin{array}{l}\text { Opinions of junior doctors regarding their past and present nutrition } \\
\text { training }\end{array}$ \\
\hline $\begin{array}{l}\text { NNEdPro semi-qualitative } \\
\text { doctor one to one interview }\end{array}$ & To see what barriers junior doctors have to nutritional care on the wards \\
\hline
\end{tabular}

Figure 1 Purpose of each evaluation method used in this review. ERimNN, Education and Research in Medical Nutrition Network. 


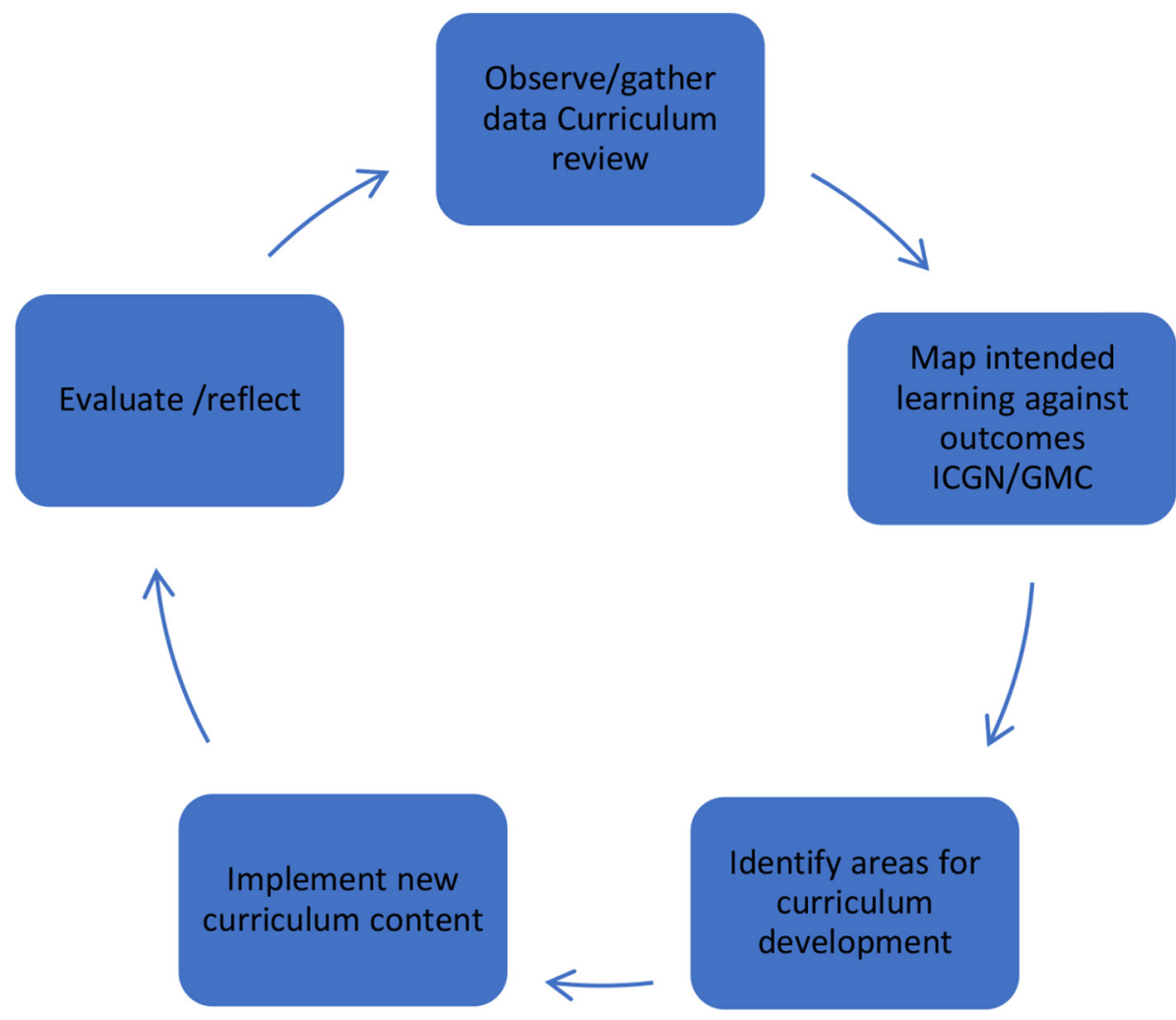

Figure 2 ERimNN action research cycle: model for integrating nutrition into the curriculum. ERimNN, Education and Research in Medical Nutrition Network; GMC, General Medical Council; ICGN, Intercollegiate Group on Nutrition.

by the Intercollegiate Group on Nutrition curriculum framework $(2013)^{16}$ and those included in the 2015 GMC 'Outcomes for Graduates'. 17

ERimNN-led module and teaching evaluations In 2016, Brighton and Sussex Medical School's (BSMS) generic module evaluations (online supplementary appendix 1) were reviewed and identified how medical students perceived the nutrition content taught the previous year, as a baseline measurement prior to an ongoing programme to improve nutrition content. Lectures where the topic was nutrition-focused were extracted and combined with evaluations of nutrition-focused student selected components (SSCs) using a 1-4 Likert scale. In addition, an evaluation of year 3 medical students before and after a malnutrition workshop (online supplementary appendix 2) was included.

A Nutritank (student medical society) survey investigated the perceptions of nutrition and nutrition education in undergraduate medical education. A cross-sectional anonymous survey was distributed to students via email to all year groups at Birmingham, Warwick and Bristol medical schools (online supplementary appendix 3).

A doctor-led survey of medical students was distributed via email and social media to $14 \mathrm{UK}$ medical schools. This survey explored student opinions of the doctor's role in nutrition, confidence in current knowledge, and reflections on how well their medical school is preparing them for professional practice in regard to nutrition (online supplementary appendix 4).
Medical students self-identified as being in either preclinical or clinical years of study and responded to Likert-scale and free-text questions. The median was used as the measure of central tendency. Mann-Whitney $\mathrm{U}$ test was used to compare the difference between preclinical and clinical student responses (significant at $\mathrm{p}<0.05$ ); non-responses were excluded from this subanalysis.

The NNEdPro-led qualitative survey of medical students was a short survey featuring 10 questions for medical students advertised on social media and completed using SurveyMonkey.

Using Likert scales, the survey aimed to establish medical students' views on their current sources of medical nutrition information and to establish whether there was a need for more accessible medical nutrition education learning materials to both complement existing resources and to provide new sources of information. The survey also enabled medical students to outline where their specific medical nutrition education gaps were.

Responses were collated and simple proportions calculated for each question. In addition, thematic analysis of free-text responses to a question exploring areas of nutrition interest and need within the medical student population was completed.

A Nutritank junior doctor survey was completed sampling junior doctors working in different specialties. A 10-question online survey was distributed via a web link to postgraduate doctors in the Midlands, South West 


\begin{tabular}{|l|l|l|}
\hline Title & Type of data & $\begin{array}{l}\text { Number of participants (n } \\
\mathbf{8 5 3} \text { ) }\end{array}$ \\
\hline $\begin{array}{l}\text { An ERImNN curriculum } \\
\text { review and student } \\
\text { evaluations }\end{array}$ & Module evaluations & $\begin{array}{l}136 / 125 \text { module evaluations } \\
18 / 18 \text { SSC evaluations } \\
72 \text { pre /42 post teaching } \\
\text { evaluations }\end{array}$ \\
\hline $\begin{array}{l}\text { A Nutritank (student } \\
\text { medical society) online } \\
\text { survey }\end{array}$ & Online survey & 244 \\
\hline $\begin{array}{l}\text { A doctor led online survey } \\
\text { of medical students }\end{array}$ & Online survey & $\begin{array}{l}181 \text { Pre-clinical (91) and } \\
\text { clinical (90) students }\end{array}$ \\
\hline $\begin{array}{l}\text { The NNEdPro led semi- } \\
\text { qualitative online survey } \\
\text { medical students }\end{array}$ & Online survey & 40 \\
\hline $\begin{array}{l}\text { A Nutritank online junior } \\
\text { doctor survey }\end{array}$ & Online survey & 142 \\
\hline $\begin{array}{l}\text { NNEdPro semi-qualitative } \\
\text { doctor one to one } \\
\text { interview }\end{array}$ & Qualitative one to one interview & 20 \\
\hline
\end{tabular}

Figure 3 Summary of included teaching evaluations and surveys. ERimNN, Education and Research in Medical Nutrition Network; SSC, student selected component.

and North West of England. Approval was gained from respective postgraduate education teams. Participants were anonymous and gave informed consent. Data were collected over a 4-month period and were descriptively analysed (online supplementary appendix 5).

A NNEdPro semiqualitative survey consisted of oneon-one interviews and Visual Analogue Scale (VAS) questionnaires. Content analysis was conducted on interview responses and VAS responses were converted to percentile scores. This allowed comparisons to be made between doctors with different scopes of focus in their care. Median and IQR were used as statistical measures (online supplementary appendix 6).

\section{RESULTS}

From our surveys and module evaluations we were able to collect five heterogeneous sources of information on current beliefs surrounding nutrition in medical education and practice, representing 853 participants, which we analysed to answer our three questions, as detailed in figure 3.

\section{Perceived importance of nutrition in clinical practice and desire for further training}

The ERimNN student evaluations of five nutrition lectures provided a mixed picture. Students scored the overall quality and interest/enjoyability a 3 or a 4 , but the usefulness of the material only a 2 or a 3 . There were no comments made on nutrition when given the opportunity to write any free comments.
Within SSC evaluations, $38.9 \%$ of students commented that they had not realised how complex nutrition was and $50 \%$ could see how doctors could engage in nutritionrelated decisions. The greatest satisfaction with the content occurred when delivered by a nutrition professional with clinical experience or with patients discussing their experiences.

In the Nutritank medical student survey, $99 \%$ of respondents felt that nutrition played a role in maintaining good health. A further $97.5 \%$ believed nutrition played a role in the development of disease and $94.6 \%$ thought that nutrition played a role in the management of disease. In addition, $88 \%$ felt that patients would expect them to have an understanding of nutrition as a doctor and $85 \%$ of participants would welcome more nutrition teaching.

In the doctor-led survey of medical students, 96\% agreed or strongly agreed that 'doctors have a responsibility to provide evidence-based advice on food and nutrition in relation to health and disease', and $68 \%$ of participants would welcome more nutrition teaching at their medical school.

In the NNEdPro semiqualitative online survey of medical students, when asked to score the importance of nutrition in their medical school curriculum, where 1 was 'not at all important' and 10 was 'extremely important', $87.2 \%$ scored between 1 and 4 . In terms of making an assessment of how their current learning needs were met in nutrition topics thus far in their training, 76.9\% scored between 1 and 4 points, indicating they did not have their learning needs met in this area. The desired 


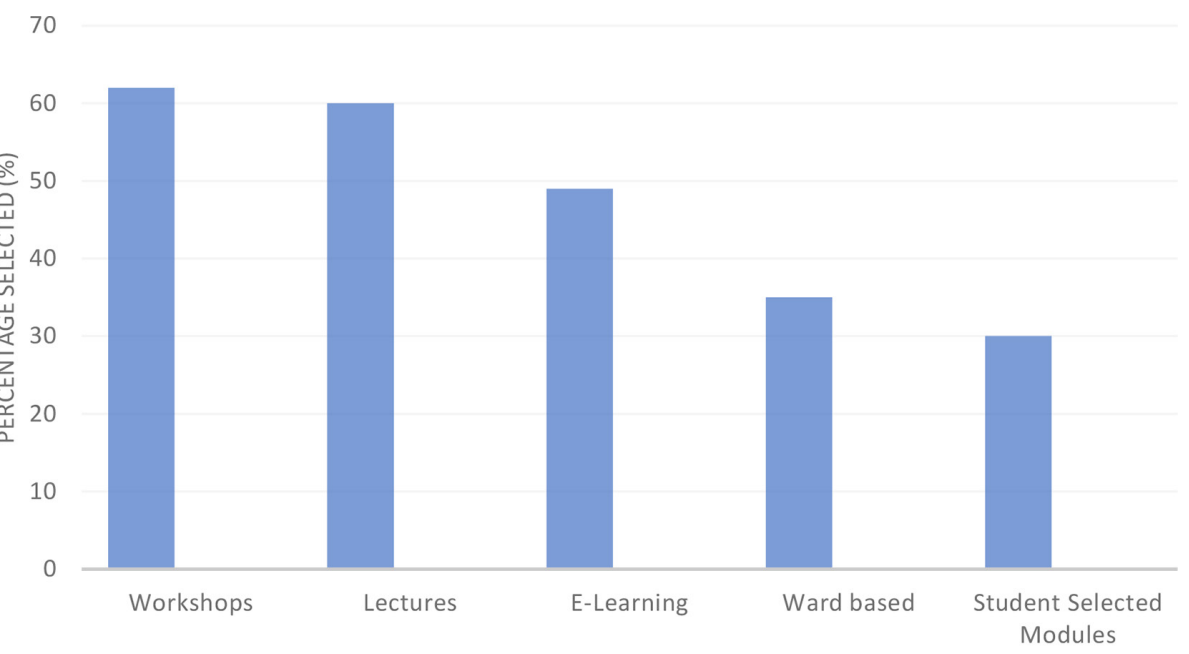

PREFERRED METHOD OF NUTRITION TEACHING

Figure 4 Nutritank student survey: preferred methods of nutrition teaching $(n=244)$.

content ranged from paediatric nutrition and nutrition in pregnancy to postsurgical nutrition and nutrition management in chronic disease (online supplementary appendix 7).

From the Nutritank junior doctor survey, 97\% agreed that nutrition played a role in maintaining good health, in the development of disease and in the management of disease. Furthermore, $91 \%$ stated they would like to receive more teaching on nutrition as part of their training.

\section{Nutrition in current training and preferred methods of learning nutrition}

The 2015 ERimNN curriculum review identified explicit nutrition content in just one module, which was within the first year of study. As such, nutrition-related knowledge, except for the single module in which it appeared, was not formally taught or assessed. The 2018 curriculum review identified an improved picture with nutritionrelated learning outcomes in eight modules, with nutrition-focused SSC or symposiums in all modules in years 1 and 2, with selected nutrition-related content in year 3 and nutrition-related research projects in year 4 .

From the Nutritank student survey, only $45 \%$ of respondents received teaching on nutrition, and of these $71.5 \%$ reported less than 2 hours (including lectures, tutorials and e-learning) in the past academic year. Of the respondents, $85 \%$ would welcome more nutrition teaching, listing preferred learning methods as in figure 4. Similarly, of those surveyed in the Nutritank doctor survey, $81 \%$ had received less than 2 hours of teaching on nutrition in the past 12 months, with $94 \%$ of respondents receiving less than 4 hours.

In the doctor-led survey, when asked whether they were receiving a "comprehensive and relevant education in diet and nutrition in relation to health and disease at medical school', $14 \%$ of students agreed or strongly agreed. Similarly, when asked whether their 'medical school prepared (or is preparing) me well on how to advise patients on diet and nutrition in relation to health and disease', only $12 \%$ agreed or strongly agreed. In both questions, there was a significant difference between the responses of the two student subgroups, with clinical students disagreeing more (median=disagree) than preclinical students (median=neither agree nor disagree) to both statements ( $\mathrm{p}=0.004$ and $\mathrm{p}<0.001$, respectively).

From the NNEdPro-led student online semiqualitative survey, $64 \%$ reported learning on their own, $38.5 \%$ with a textbook, while $49 \%$ used websites. Furthermore, $23 \%$ used journal articles, $10 \%$ used review books, $8 \%$ used video courses and a further $8 \%$ did not use any resources. Of the respondents, $10 \%$ reported using 'other', where free-text responses showed they made use of a nutrition handbook given to them in year 1 of their course, news articles, lectures and time spent on placement with a dietitian. When asked to score how difficult it was to locate resources to support their medical nutrition learning needs, $55 \%$ scored between 1 and 4 points, indicating that the majority found it difficult, with over one-fifth scoring 1 , indicating they found it extremely difficult.

From the interviews with Cambridge junior doctors, they commented that nutrition training during their medical degree was minimal or implicit, then informal or absent during their career development. However, there was a suggestion that teaching should be given in person rather than online and included throughout the curriculum rather than a one-off session.

\section{Confidence in nutrition knowledge, skills and self-perceived role of doctors in nutritional care}

ERimNN completed preteaching and post-teaching evaluations of a nutrition workshop within a single cohort of students $(n=72)$. Prior to the taught session, $83 \%$ reported themselves as 'not confident at all' or 'not very confident', and none self-identified as being either confident or very confident in completing a nutrition assessment. A post-teaching questionnaire was completed by 


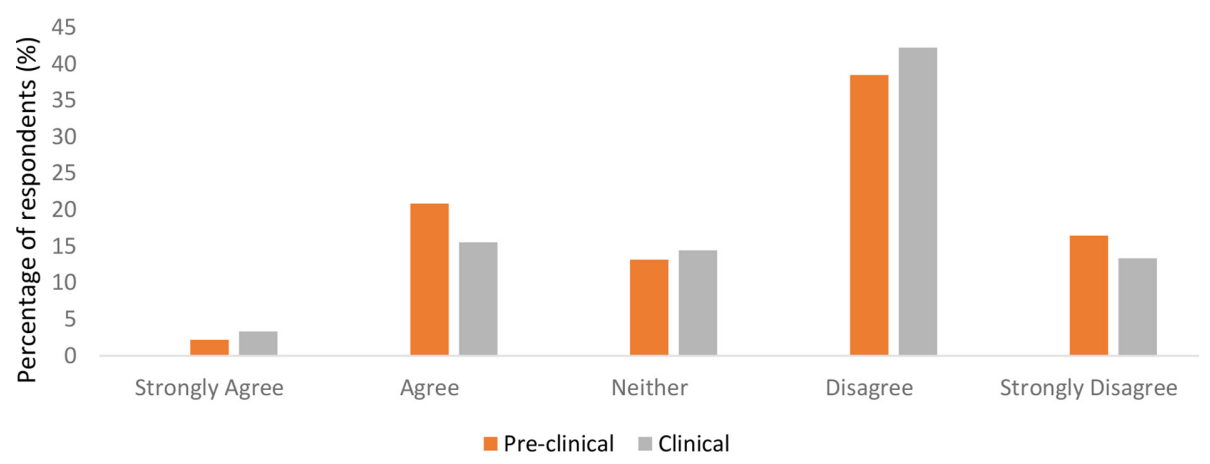

Figure 5 Doctor-led survey: medical students' confidence in their knowledge of current UK nutrition and diet guidelines $(n=163)$.

students $(\mathrm{n}=42 / 72)$, of whom $58.3 \%$ identified as confident or very confident.

From the doctor-led survey, few medical students were confident in their knowledge of current UK dietary guidelines, as shown in figure 5. In relation to students' confidence in their 'current knowledge on diet and nutrition in relation to health and disease' and in 'advising patients', they were evenly distributed between agree and disagree, with no significant difference between preclinical and clinical students' confidence in these areas ( $\mathrm{p}=0.869$ and $\mathrm{p}=0.167$, respectively) (figures 6 and 7 ).

From the Cambridge doctor interviews, when asked about a doctor's responsibilities in nutritional care, $75 \%$ mentioned a multidisciplinary approach, for example, 'team', 'other specialists' and 'dietitians', and 55\% mentioned specific roles, for example, 'coordination of care' and 'initiation of conversation' for doctors.

When asked where they identified boundaries to clinical implementation of nutrition, respondents indicated that written and spoken communications between doctors, patients and other professionals are key limiting factors by $40 \%$ of those surveyed, with $65 \%$ responding that further nutrition training is necessary or would be beneficial and $40 \%$ identifying consultants as those best placed to promote nutrition.

From the VAS, three (15\%) respondents had less than $50 \%$ confidence in making nutrition referrals. Using the VAS scale, participants were asked how nutritional care could be improved; the median estimated percentage efficacies (median (IQR)) were 40.5\% (21/80), 56.5\% $(32 / 78)$ and $87 \%$ (76/94) for intensive weekend courses, nutrition awareness weeks and introduction of nutrition protocols, respectively.

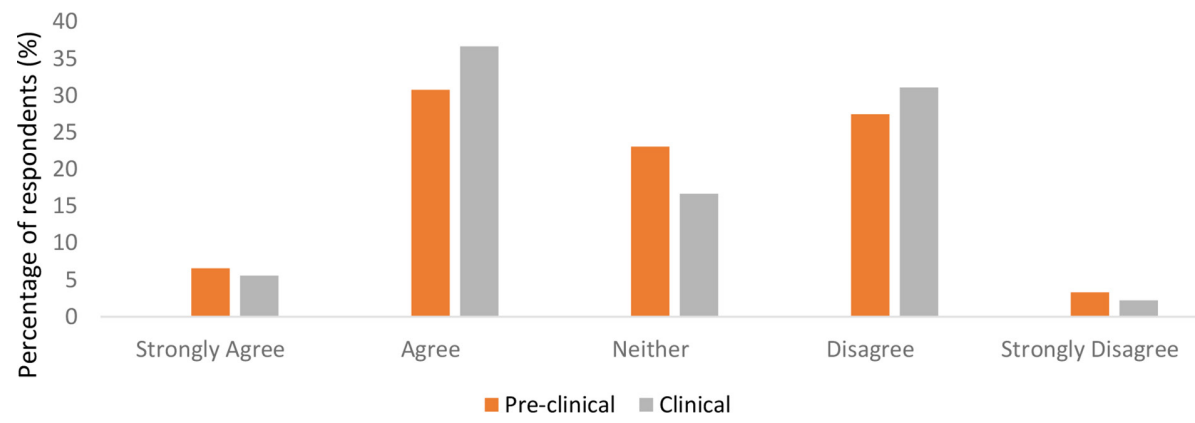

The Nutritank junior doctor survey demonstrated that $92 \%$ of participants believed patients expect them to have an understanding of nutrition as a doctor, yet only $26 \%$ felt confident discussing nutrition. Of the participants, $74 \%$ stated that they only gave nutritional advice or discussed nutrition with patients once a month or less, citing lack of knowledge (75\%), lack of time $(64 \%)$ and lack of confidence $(62 \%)$ as the main reasons for this infrequency. Additionally, 38\% did not consider nutrition when making management plans and $28 \%$ preferred to get specialist advice.

\section{DISCUSSION}

Emerging evidence suggests that UK medical students feel underprepared to address nutrition-related issues once qualified. ${ }^{12}$ However, within current literature there is minimal evidence of the extent of nutrition content in UK medical schools, doctors' competence in nutritional care or the role of nutrition in UK medical practice. Furthermore, it remains unclear where nutrition education gaps lie and subsequently where we should be targeting improvements given the limited time available in medical curricula. This paper, as a landscaping exercise, can act as a starting point from which future research can develop.

\section{Amount of nutrition content in training and preferred methods of learning nutrition}

Consistently, participants felt that nutrition education was inadequate, which perhaps is unsurprising as responders are likely to be biased to those already with an interest in nutrition, but is reflective of previous findings. ${ }^{13} 1418$

Figure 6 Doctor-led survey: medical students' confidence in their knowledge of diet and nutrition ( $n=166)$. 


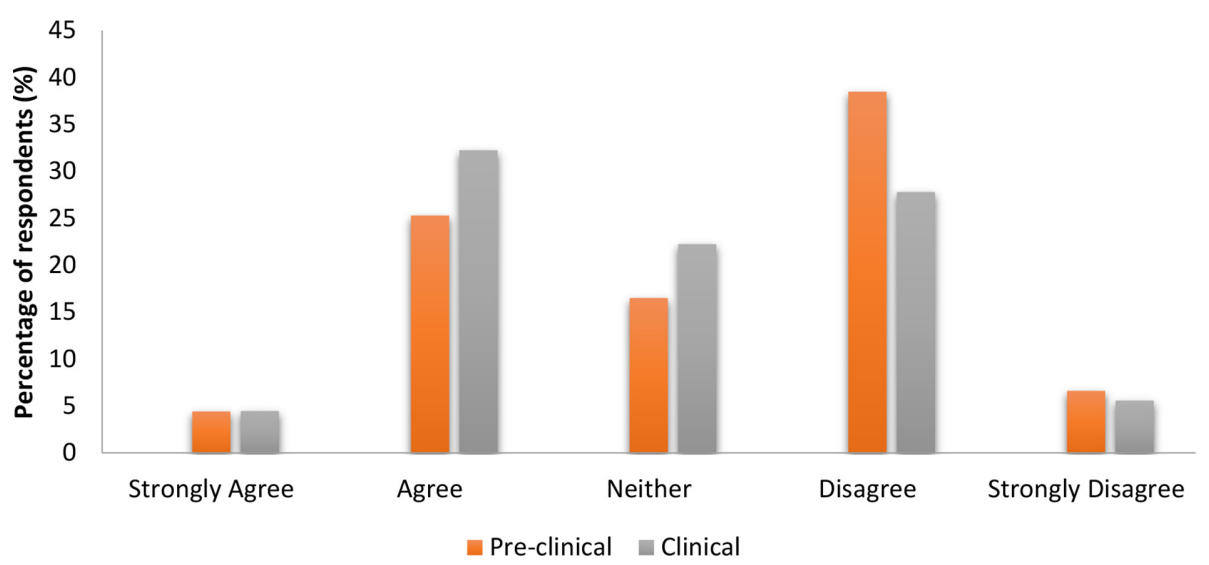

Figure 7 Doctor-led survey: medical students' confidence in advising patients on diet and nutrition ( $\mathrm{n}=166)$.

In contrast, within one medical school where all medical students participated, students enjoyed nutrition teaching, but overall scored the relevance of this teaching lower, suggesting that interest may be exaggerated due to responder bias. Despite this reported enjoyment of nutrition teaching, the relevance of nutrition to their medical practice remains unclear, warranting further research.

The reasons behind this perceived inadequacy of medical nutrition education in the UK are unknown, although in the USA barriers cited include lack of space in the curriculum, frequent changes in course leaders and teaching priorities, and lack of resources and credible nutrition educators working in medical schools. ${ }^{19}$

Preferences for how nutrition-related knowledge should be delivered varied. Doctors reported a preference for inperson rather than online teaching, while British Medical Association (BMA) students preferred workshops and lectures and struggled to locate appropriate nutrition resources to supplement their education. As the sample is small, it is difficult to draw robust conclusions, but taking a pragmatic approach it is important to consider how to scale nutrition education with limited resources, for example, whether to promote online modules or nutrition textbooks to accompany current core medical textbooks.

Despite challenges, improvement in nutrition-related curriculum content is possible, as is evident within BSMS and other medical schools. ${ }^{20}$ However, further work is required to compare nutrition curricula and the effectiveness of different teaching methods across UK medical schools. This will allow better understanding of how to build capacity and efficacy of nutrition education, as well as identifying best practice to direct future nutrition resources and promote continued learning.

\section{Confidence in nutrition knowledge, skills and self-perceived role of doctors in nutritional care}

Medical students felt that patients expect doctors to be a credible source of nutrition information, which aligns with research into actual patient expectations. ${ }^{10} 21$ However, doctors and students recognised they had limited nutrition knowledge, which also reflects previous findings. ${ }^{22-24}$
Furthermore, despite $97 \%$ of doctors reporting nutrition as a vital part of health, three-quarters discussed nutrition with their patients less than once a month. This suggests that even when perceived importance is high doctors may be unable to translate this into practice. Further research is needed on how to enable doctors to realistically include nutrition within existing clinical pressures and competing priorities.

Other than recognising doctors' need for more training, ${ }^{3}$ there is little guidance on how enhancing knowledge can be translated into clinical practice, or indeed the specific role of a doctor within a multidisciplinary team providing nutritional care.

A positive finding from a small sample of Cambridge doctors was the recognition that nutritional care requires collaboration between disciplines, but it is unclear if this view is representative, and further research into roles and responsibilities for nutritional care is needed. From the same sample, only $28 \%$ of doctors preferred to get specialist advice on nutrition; however, it is unclear what they consider 'specialist advice' to be and what their current referral practices to dietitians are.

Particularly seen in hospital settings, the multidisciplinary approach to patient care allows each profession to have a discrete role in optimising a patient's nutrition while collectively covering all aspects of care. Enhancing the role of doctors, nurses and other healthcare professionals alongside the expertise of dietitians may help to address capacity issues and better manage resources.

\section{Perceived importance of nutrition in clinical practice and desire for further training}

Across all surveyed participants there was $>90 \%$ agreement from medical students and doctors on the importance of nutrition in maintaining health. Alongside this there was strong agreement that it is a doctor's responsibility to provide evidence-based nutritional advice and recognition of the importance nutrition management can make to both the patients and the general population. Most expressed a desire for further nutrition teaching, but there remains uncertainty about the role of the doctor in nutrition management. Without clear expectations to 
reflect the diverse setting in which doctors work, identifying any further training that might be required is difficult. $^{2526}$

An interesting dichotomy within this small sample of likely interested medical students emerged from the data, warranting further research. It seems that in some cases medical students have identified that nutrition is important, but have not expressed a desire for more training. This may reflect the importance of nutrition at a personal level, which is then not evident within professional practice. Similar observations have been made of other health professionals, who profess that nutrition is important in patient care and recovery, but unfortunately do not then translate this into planned nutritional support. ${ }^{27}{ }^{28}$ This lack of professional practice is possibly due to the absence of existing doctors acting as role models to demonstrate nutritional care. Role modelling is seen as an essential aspect of medical training. ${ }^{27}$ Therefore, further research could explore how often seniors are seen discussing nutrition and how this could influence the professional practice of future doctors. Without this, junior doctors or students are unlikely to develop appropriate conversational tools to discuss diet and nutrition. Although this was not fully explored in this paper, $40 \%$ of doctors in one survey felt medical consultants were best placed to promote nutrition. Again, the sample size here is limited and warrants further investigation into roles and responsibilities at different medical grades.

\section{Plan for further intervention}

Reviewing this collection of surveys, numerous gaps in the research surrounding current nutrition education content and practice have been explored. In addition, a number of new themes have been identified.

One such area that requires further exploration is how different professional groups, including doctors, perceive their role in providing nutritional care. This is important to identify professional responsibilities within nutritional care pathways, including where aspects are likely to be missed. While there is a clear need to improve nutritional care in both primary and secondary care settings, it is essential to provide focus on the development of nutrition education resources that support new students' and existing doctors' professional nutrition development.

The curriculum review at BSMS has demonstrated that it is possible to integrate nutrition within a medical curriculum. Currently there are collaborative efforts under way to improve nutrition education for medical students and doctors via the UK multiprofessional nutrition education working party. ${ }^{29}$

Alongside this, national collaboration between organisations such as NNEdPro, Nutritank and ERimNN has coordinated efforts to increase capacity and to disseminate a clear message that further nutrition training in medical education is desired and necessary for safe medical practice. One such project is the NEPHELP project developed by NNEdPro.

\section{Strengths of this comparative paper}

As a collective group, the surveys provided a sample of good size, which provided a number of insights from different levels of training, including UK medical students and doctors.

Further to this, the surveys explored similar themes around aspects of training using different techniques. By doing so it allows a collection of insights through qualitative work and quantitative surveys.

\section{Limitations of this study}

There are limitations to this study, both as a collection of work and individually. As a collection these surveys and evaluations have not been validated and all suffer from selection bias, as by nature those most likely to respond and complete the surveys will have an interest in this topic. In addition, participants are likely to assume that the survey was designed to increase nutrition content, and therefore they may tailor their answers to align in this fashion. Further to this the lack of standardisation between surveys and evaluation techniques means there is less comparability between reviews, and alongside this the questions chosen may not accurately reflect the manner of education chosen by their university.

Respondents only represent a small percentage of UK medical students and junior doctors, although low response rates are common, evident in other surveys and evaluations. ${ }^{20} 23$

This synthesis of surveys has been brought together to facilitate a multifaceted landscaping exercise regarding nutrition education of doctors in training in the UK. It has used a range of different methods, through convenience sampling and using open surveys to assess trends in self-selected respondents. While these results cannot be considered as representative of the entire population of medical trainees, the strong agreement in either trends or themes emerging from the different instruments used for data collection would suggest that none of the individual substudies in this paper comprise majorly skewed results. This gives a level of confidence that allows us to broadly synthesise the collective results into a current state of play of gaps in nutrition knowledges and practices within the medical workforce. Despite the methodological limitations, this paper still constitutes the greatest coverage to date of the issue at a level that looks widely across the nation.

\section{CONCLUSION}

This narrative review provides a collective description of the current state of medical nutrition training within UK medical school and foundation programme curricula. Apart from suggesting that UK medical school curricula are providing insufficient training for doctors to counsel their patients on nutrition, it has identified potential gaps where training-based solutions can be implemented.

While the heterogenicity of this review does provide challenges in data interpretation, it delivers a wide range of different insights. In publishing these data, instead of 
curriculum panels reviewing their own feedback, these results can be critiqued and commented on to provide more uniform approaches to standards of nutrition education. This will prove vital in the formation of a national examination which is due to be set for medical schools in the near future across the UK.

It remains apparent that we need to reform medical curricula in the UK to address the current lack of skill and knowledge doctors are reporting in giving nutritional advice, while pushing the multidisciplinary culture to assign and take responsibility for different roles in nutritional care.

\section{Author affiliations}

${ }^{1}$ Nutrition and Dietetics, Brighton and Sussex University Hospitals NHS Trust, Brighton, UK

${ }^{2}$ NNEdPro Global Centre for Nutrition and Health, St John's Innovation Centre, Cambridge, UK

${ }^{3}$ School of Clinical Medicine, Addenbrooke's Hospital, University of Cambridge, Cambridge, UK

${ }^{4}$ Bristol Medical School, University of Bristol, Bristol, UK

${ }^{5}$ York Teaching Hospital NHS Foundation Trust, York, UK

${ }^{6}$ School of Health Sciences, University of Brighton, Brighton, UK

Correction notice The article has been corrected since it was published online first. The affiliation of some of the co-authors have been updated.

Twitter Elaine Macaninch @macaninch

Acknowledgements The authors acknowledge Aeisha Alexander, Karen Chamberlain, Síle Griffin, Jorgen Johnsen, Rachel Keane, Jessicarr Moorhouse, Flo Mouy and Catherine Peutherer, as well as the following organisations: NNEdPro Global Centre for Nutrition and Health, MNI International, AIM Foundation, ERimNN, Nutritank, NHS, Medical Research Council, University of Cambridge, University of Bristol, and Brighton and Sussex Medical School.

Contributors EM: analysis of Brighton data and synthesis of study findings. LB: analysis of junior doctor data and synthesis of study findings. PA: Cambridge data analysis and student interviews. IB: design and analysis of Nutritank online survey (students and doctors). $\mathrm{HC}$ : design and analysis of Cambridge junior doctors survey. DC: design and analysis of junior doctors online survey. RG: Cambridge junior doctors survey and medical students survey. DH: Cambridge junior doctors survey and medical students survey. AJ: design and analysis of Nutritank online survey (students and doctors). MR-R: guidance on data analysis and synthesis of findings. KM: planning of project and collection of University of Brighton data, and identified method for synthesis of heterogeneous data sources. SR: contributed to data synthesis and planning of Cambridge data.

Funding The study was funded by an education grant from MNI Award and AIM Foundation.

Competing interests None declared.

Patient consent for publication Not required.

Provenance and peer review Not commissioned; externally peer reviewed.

Data availability statement All data relevant to the study are included in the article or uploaded as supplementary information. Data are held at the University of Brighton repository and are available upon reasonable request through the corresponding author (KM) on publication.

Open access This is an open access article distributed in accordance with the Creative Commons Attribution Non Commercial (CC BY-NC 4.0) license, which permits others to distribute, remix, adapt, build upon this work non-commercially, and license their derivative works on different terms, provided the original work is properly cited, appropriate credit is given, any changes made indicated, and the use is non-commercial. See: http://creativecommons.org/licenses/by-nc/4.0/.

\section{REFERENCES}

1 Newton JN, Briggs ADM, Murray CJL, et al. Changes in health in England, with analysis by English regions and areas of deprivation,
1990-2013: a systematic analysis for the global burden of disease study 2013. The Lancet 2015;386:2257-74.

2 Webb P, Stordalen GA, Singh S, et al. Hunger and malnutrition in the 21st century. BMJ 2018;361:k2238.

3 National Health Service. The NHS long term plan. Available: https:// www.longtermplan.nhs.uk/wp-content/uploads/2019/01/nhs-longterm-plan-june-2019.pdf [Accessed 5 Jul 2019].

4 Russell CA, Elia M. Nutrition screening surveys in hospitals in the UK, 2007-2011. British association for parenteral and enteral nutrition, Redditch, UK, 2014.

5 NHS England. Guidance - commissioning excellent nutrition and hydration $2015-2018,2015$.

6 Public Health England and the Food Standards Agency. National diet and nutrition survey years 1 to 9 of the rolling programme (2008/2009 - 2016/2017): time trend and income analyses, 2019.

7 Elia M. The cost of malnutrition in England and potential cost savings from nutritional interventions (full report). BAPEN and NICE: Southampton, 2015.

8 Public Health England. Health matters: obesity and the food environment, 2017.

9 Kahan S, Manson JE. Nutrition counseling in clinical practice: how clinicians can do better. JAMA 2017;318:1101-2.

10 Ball LE, Hughes RM, Leveritt MD. Nutrition in general practice: role and workforce preparation expectations of medical educators. Aust $J$ Prim Health 2010;16:304-10.

11 Cash T, Desbrow B, Leveritt M, et al. Utilization and preference of nutrition information sources in Australia. Health Expect 2015;18:2288-95.

12 Womersley K, Ripullone K. Medical schools should be prioritising nutrition and lifestyle education. BMJ 2017;359:j4861.

13 Devries S, Dalen JE, Eisenberg DM, et al. A deficiency of nutrition education in medical training. Am J Med 2014;127:804-6.

14 Devries S, Willett W, Bonow RO. Nutrition education in medical school, residency training, and practice. JAMA 2019;321:1351-2.

15 Lee V, Coombe L, Robinson P. Building capacity through action research curricula reviews. High Educ Res Dev 2015;34:324-37.

16 Academy of Medical Royal Colleges Intercollegiate Group on Nutrition. Uk: undergraduate curriculum in nutrition 2013.

17 General Medical Council (GMC). Outcomes for graduates 2018, 2015. Available: https://www.gmc-uk.org/-/media/documents/ dc11326-outcomes-for-graduates-2018_pdf-75040796.pdf

18 Adams KM, Kohlmeier M, Zeisel SH. Nutrition education in U.S. medical schools: latest update of a national survey. Acad Med 2010;85:1537-42.

19 Dimaria-Ghalili RA, Edwards M, Friedman G, et al. Capacity building in nutrition science: revisiting the curricula for medical professionals. Ann N Y Acad Sci 2013;1306:21-40.

20 Long W, Neild P. PTH-133 Nutrition Training in UK Medical Undergraduate Programmes - Has The Situation Improved? Gut 2016;65:A285.2-6. 2016.

21 American Dietetic Association. Nutrition and you: trends 2008, 2008. Available: http://www.eatrightpro.org/ /media/eatrightpro\%20files/ media/trends $\% 20$ and\%20reviews/nutrition\%20and\%20you/trends _ 2008_where_did_you_hear_that.ashx).[Accessed 2017January 6th]

22 Vetter ML, Herring SJ, Sood M, et al. What do resident physicians know about nutrition? an evaluation of attitudes, self-perceived proficiency and knowledge. J Am Coll Nutr 2008;27:287-98.

23 Nowson CA, O'Connell SL. Nutrition knowledge, attitudes, and confidence of Australian general practice registrars. J Biomed Educ 2015;2015:1-6

24 Ray S, Rajput-Ray M, Ball L, et al. Confidence and attitudes of doctors and dietitians towards nutrition care and nutrition advocacy for hospital patients in Kolkata, India. J Biomed Educ 2015;2015:1-6.

25 Kopelman P, Lennard-Jones J. Nutrition and patients: a doctor's responsibility. Clin Med 2002;2:391-4.

26 Mogre V, Scherpbier AJJA, Stevens F, et al. Realist synthesis of educational interventions to improve nutrition care competencies and delivery by doctors and other healthcare professionals. BMJ Open 2016;6:e010084.

27 O Connell MB, Jensen PS, Andersen SL, et al. Stuck in tradition-A qualitative study on barriers for implementation of evidencebased nutritional care perceived by nursing staff. $J$ Clin Nurs 2018;27:705-14.

28 Zanini M, Bagnasco A, Aleo G, et al. Returning to the sacred - the importance of careful attention to patients' nutritional needs in hospital settings. J Adv Nurs 2017;73:523-6.

29 Association For Nutrition. Transfer of undergraduate medical curriculum in nutrition, 2018. Available: http://www.associationfornu trition.org/Portals/0/Public/News\&Events/AfN\%20Statement;\% 20Transfer\%20of\%20Undergraduate\%20Medical\%20Curriculum\% 20 in\%20Nutrition\%20to\%20AfN\%20Release.pdf 